\title{
CONTOS DE GRIMM E NOVOS CONTOS DE GRIMM: TRADUÇÃO E ADAPTAÇÃO EM MONTEIRO LOBATO
}

\author{
Sylvia Maria Trusen* \\ Universidade Federal do Pará
}

\begin{abstract}
Resumo: É conhecido o trabalho de Monteiro Lobato no campo da produção literária para o público infantil, como também o é seu esforço em emancipar o gênero dos cânones europeus. Contudo, sua tarefa de tradutor, ao realizar o traslado e a circulação de um grande número de obras estrangeiras para o ambiente nacional, parece contradizer seu projeto de fundar uma literatura infantil brasileira. A partir do exame da recepção da coletânea dos Grimm em sua obra, especialmente as adaptações Contos de Grimm e Novos Contos de Grimm, pretende-se, pois, vislumbrar o modo pelo qual Lobato teria conciliado os propósitos aparentemente em desacordo.
\end{abstract}

Palavras-chave: Tradução. Leitura. Recepção.

\footnotetext{
* Possui graduação em Letras pela Faculdade de Ciências e Letras Notre Dame (1983), mestrado em Letras pela Universidade Federal do Ceará (1995) e doutorado em Letras pela Pontifícia Universidade Católica do Rio de Janeiro (2006). Atualmente é membro conselho editorial - LER - Leitura em Revista, editada pela Cátedra Unesco de Leitura- Professora adjunta da Universidade Federal do Pará, Professora do Programa de Pós-Graduação Linguagens e Saberes na Amazônia, e pesquisadora da Cátedra Unesco de Leitura PUC-Rio/RELER. Belém, Pará, Brasil. E-mail: sylviatrusen@me.com/sylviatrusen63@gmail.com
} 


\title{
CONTOS DE GRIMM AND NOVOS CONTOS DE GRIMM: TRANSLATION AND ADAPTATION BY MONTEIRO LOBATO
}

\begin{abstract}
Monteiro Lobato's work is well known in the field of literature for children, and so is his effort to emancipate the genre of European canons. However, his task as translator to transfer and circulate a large number of foreign literature works within the national environment, seems to contradict his project of founding a own Brazilian children's literature. With the review of the reception of the Grimm's collection in his work, especially the adaptations of Grimm Fairy Tales and the New Tales of Grimm, the task is therefore to analyse how Lobato has reconciled the purposes in apparently disagree.
\end{abstract}

Keywords: Translation. Reading. Reception.

\section{Tradução e leitura}

"Traduzir é tarefa mais delicada e difícil que existe (....)" (LOBATO, 1964, p. 127), escreve o autor de Narizinho em artigo no qual tece reflexões em torno da prática a qual se dedicaria intensamente, sobretudo após sua quebra na Bolsa de Valores. A afirmação de Lobato serve aqui, pois, para introduzir tema que, se é efetivamente espinhoso e delicado, exige de quem dele se acerca esclarecimento prévio do rumo que pretende adotar.

Com efeito, o vasto número de posturas teóricas, que recobrem desde questões tão pragmáticas como direitos autorais, até problemas relativos à formação de identidades culturais a partir do confronto com o texto estrangeiro (VENUTI, 2002; BERMAN, 1984), exige do pesquisador delimitação prévia. Convém, assim, esclarecer que o olhar lançado sobre essa atividade é o do comparatista que, não descurando dos problemas dos estudos da linguagem, preocupa-se com a tradução como operação necessária e previamente ancorada na leitura. Esta afirmação tem de antemão duas implicações significativas para o exame a que se quer proceder 
A primeira delas, aponta não só para a difusão no tempo e no espaço dos signos, - aspecto bastante explorado pelo After Babel ${ }^{1}$ de Steiner -, como também assinala o poder fundador da linguagem na constituição do sujeito e seus modos de apreensão da realidade. Significa isso dizer que a tradução efetiva-se não só nos processos de resignificação - com todas as possibilidades advindas do confronto entre as línguas/culturas, mas também como operação inerente aos atos de comunicação. De fato, conquanto reconheça que o sentido mais restrito da tradução resida no contato entre idiomas distintos, Steiner sustenta que, se entender está diretamente associado ao ato de decifrar mensagens, no limite, "el ser humano se entrega a un acto de traducción en el sentido cabal de la palabra cada vez que recibe de otro un mensaje hablado." (STEINER, 2001, p. 50)² A força retórica da argumentação do After Babel erige-se, em parte, sobre a observação da movimentação no espaço e no tempo de uma ou mais línguas, de tal modo que o ato da tradução se faz necessário, por exemplo, para lidar com as transformações no seio de um mesmo idioma. O viés dado por Steiner permitiu, por sua vez, ao pensador espanhol Larrosa enlaçar tradução e leitura, reivindicando, a partir deste par conceitual, o valor metafórico da tradução. Desse modo, acentua, nesta operação, a carga semântica de transformação:

Translado, transformación mutua, familiarización de lo extraño, extrañamiento de lo familiar, intermediación. En la traducción, como en la lectura, siempre es cuestión de un juego de diferencias. Entre las lenguas entre el libro y el lector, entre cada lengua y ella misma por mediación de la lengua extranjera, entre el libro y él mismo a través del lector, entre el lector y si mismo gracias al libro, entre las palabras y las cosas, entre la biblioteca y la productividade permanente del sentido. La tradución, como la lectura, tienen su lugar en un entre (LARROSA, 1996, p. 303).

O trecho citado, apesar de longo, tem para a investigação da recepção do acervo dos Irmãos Grimm diversas consequências. Em 
primeiro lugar, porque permite ao pesquisador situar o trabalho de Lobato como atividade que repousa sobre o ato de leitura, que não se reduz ao trânsito entre idiomas distintos, mas se situa também no âmbito da própria língua; em segundo, porque acentua - aspecto fundamental, como se verá - a dinâmica da transformação neste jogo do qual participam leitor e texto.

Do enlace tradução/leitura, retira-se ainda uma segunda implicação, especialmente relevante para quem lida com os problemas do comércio ente as literaturas. Com efeito, não são poucos os que têm anotado a função da tradução como mecanismo indispensável de circulação literária. De fato, o texto traduzido, situado na difícil fronteira entre duas línguas, transita de um público a outro, viabilizando o contato e as transformações nos sistemas literários a que pertencem. Em outros termos, isso significa dizer que, também considerada no âmbito interlingual (JAKOBSON, 1995, p. 63), a tradução implica um processo de reconhecimento dos horizontes de leitura do novo público receptor, implicando, pois, uma modificação do texto de partida.

Com efeito, recorrendo à estética da recepção de Jauss, o comparatista Chevrel observa que o problema da tradução reside justamente no fato desta se movimentar entre dois horizontes de leitura distintos (CHEVREL, 1989, p. 57). Se o original já se define pela tensão criada entre a expectativa de seu leitor e a gerada pela obra, seu tradutor irá lidar com um público, cujo idioma configura um horizonte distinto do que preside o texto-emissor. Consequentemente, argumentam os autores de Que é literatura comparada, "as traduções pertencem à literatura que as acolhe e se integram no seu patrimônio. Julguemo-las, pois, pela necessidade que as faz nascer." (BRUNEL; PICHOIS; ROUSSEAU, 1990, p. 134) Nesse sentido, a prática da tradução desvela e põe em xeque noções caras ao ocidente moderno, como autoria, originalidade, cânone, literatura nacional. E, no limite, não só relê o texto de partida, como obriga ao sistema literário que o recebe a modificar-se.

Com efeito, a passagem de um texto a outro, carreando consigo toda a cultura imbuída na língua de partida para a língua-alvo, não 
ocorre de forma tão pacífica quanto pode deixar transparecer o trabalho final do tradutor. Há, previamente, entre a leitura do original e o texto em tradução, uma gama variada de decisões a serem tomadas, decorrentes do embate entre o horizonte de expectativas do público ao qual se dirige o texto e aquele ao qual a obra originariamente se destinava. Como dinâmica, portanto, que se movimento entre textos, a tradução é marcada por ambivalências. É, pois, com razão que Berman pleiteia uma "ética da tradução":

Or, la traduction occupe ici une place ambiguë. D'une part, elle se plie à cette injonction appropriatrice et réductrice, elle se constitue comme l'un de ses agents. Ce qui donne des traductions ethnocentriques, ou ce que l'on peut appeler la 'mauvaise traduction'. Mais d'autre part, la visée éthique du traduire s'oppose par nature à cette injonction: l'essence de la traduction est d'être ouverture, dialogue, métissage, décentrement. Elle est mise en rapport, ou elle n'est rien (BERMAN, 1984, p. 16).

Esta ambivalência a que se refere Berman parece ser particularmente sentida por Monteiro Lobato. Afirmando a necessidade urgente de traduzir-se mais e melhor no Brasil da Belle Époque, observa a capacidade da tradução de dilatar as culturas, forçando-as para além de seus limites:

A literatura dos povos constitue [sic] maior tesouro da humanidade, e povo rico em tradutores faz-se realmente opulento, porque acresce a riqueza de origem local com a riqueza importada. Povo que não possue [sic] tradutores torna-se povo fechado, pobre indigente, visto como só pode contar com a produção local (LOBATO, 1964, p. 128).

O comentário de Lobato, ainda que fazendo jus às promessas da tradução de fecundar a literatura local mediante o contato com 
o alheio, não será reforçada, entretanto, por certa predileção do autor e tradutor pela domesticação do texto estrangeiro. Assim, sugere aos que se dedicam à tarefa, que a "tradução tem que ser um transplante. $\mathrm{O}$ tradutor necessita compreender a fundo a obra e o autor, e reescrevê-la em português como quem ouve uma história e depois a conta em palavras suas" (LOBATO, 1964, p. 128).

Com efeito, as traduções e adaptações dos contos de Grimm ver-se-á adiante-, confirmam o propósito de Lobato, não só de ampliar o repertório nacional de histórias para crianças, mas também o de ajustar um vasto acervo extraído da literatura mundial para o público brasileiro. O emprego das expressões "palavra suas" e "transplante", parece pois, não ser fortuito e nele reverbera o processo criativo lobatiano de trasladar para o Sítio diversos personagens do fabulário infantil e juvenil adequando-os ao modus vivendi local. Reconhecendo efetivamente a importância do trabalho do tradutor, opta, todavia, por domesticar o texto estrangeiro ao lugar da recepção forçando sua adequação à cor e forma local:

\begin{abstract}
O bom tradutor deve dizer exatamente a mesma coisa que o autor diz, dentro da sua língua de tradutor, dentro de sua forma literária de tradutor; só assim estará realmente traduzindo o que importa: a ideia, o pensamento do autor (LOBATO, 1964, p. 118).
\end{abstract}

Para um escritor como Lobato, que persegue o ideário iluminista, a lealdade à ideia e ao pensamento do texto original deve constituir, de fato, a meta ser atingida. Sua escolha por nacionalizar o texto estrangeiro, tornando-o palatável e de fácil leitura para seu público parece, efetivamente, obedecer ao projeto ilustrado lobatiano.

Ciente dos horizontes de expectativa de seu público alvo e conhecendo os liames que unem tradução e leitura, atenta igualmente às demandas do mercado por traduções dirigidas às crianças brasileiras, na passagem entre a Velha e Nova República. 


\section{Lobato: tradutor, empresário, escritor}

O jovem nascido em Taubaté que acalentara os mesmos sonhos dos senhores de café, ao mudar, como tantas vezes o faria, o rumo de sua vida, não desconhece o estreito vínculo que une investimento e mercado. Significa isso dizer que sofrer as oscilações de um mercado, típicas de um país em processo de desenvolvimento, requer para Lobato, um domínio de táticas literárias que combatam os prejuízos daí oriundos. Se a criação de uma literatura infantil nacional voltada ao público infantil é uma delas, a tradução o é igualmente, e mantém com a primeira um vínculo extremamente profícuo.

Nitidamente influenciado pelo modelo norte-americano, confiante nos benefícios da livre-iniciativa, Lobato empreenderá uma campanha pela modernização do país, que inclui, como bem observou Marisa Lajolo (1983), o projeto de capacitar, pela propaganda e melhor distribuição, um sistema de produção e circulação de literatura. Numa época em que o censo demográfico contabiliza para uma capital como a de São Paulo uma população total de 579.003, dos quais $58 \%$ eram registrados como alfabetizados, contando apenas com 02 editoras capazes de ultrapassar a marca de publicação superior a 30 obras e de apenas quatro que atingiram a cifra de 100.000 exemplares lançados (FIORENTINO, 1982, p. 115), Lobato reconhece, no descompasso entre público potencial e real, a inexistência de um mercado editorial eficiente que concebesse a literatura como bem de consumo. "Faço livro", diz, "e vendo-os porque há mercado para a mercadoria; exatamente o negócio de que faz vassouras e vende-as, do que faz chouriços e vende-os" (LOBATO, 1964, II V., p. 211).

À par da provocativa comparação, nota-se aí a arguta percepção do lugar dedicado à literatura dirigida ao público infantil, ficcional ou de cunho didático, consciente que estava, fosse como editor ou escritor, do papel desempenhado por esta faixa do público consumidor, privilegiado no surto de urbanização e massificação da cultura. Assim, escreve ao amigo Rangel: Estamos refreando as edições literárias para a intensificação das escolares. O bom negó- 
cio é o didático. Todos os editores começam com literatura geral e, por fim, se fecham na didática (LOBATO, 1964, II V, p. 264).

Com efeito, a importância atribuída à empresa editorial, enquanto mecanismo imprescindível para a circulação do livro naquele século, advém da sua prática como autor de textos endereçados à infância.

O meu Narizinho, do qual retirei 50.500 - maior edição do mundo! - tem que ser metido bucho a dentro do público, tal qual fazem as mães com o óleo de rícino. Elas apertam o nariz da criança e enfiam a droga e a pobre criança ou engole ou morre asfixiada. Gastei 4 contos num anúncio de página inteira num jornal daqui (LOBATO, 1964, II V, p. 230).

A larga tiragem, de fato assombrosa para as precárias condições de assimilação da época, escoa para um destinatário específico cena que testemunha a sólida aliança mantida desde os primórdios entre a narrativa para as crianças e a pedagogia. Donde, não é casual que tenha sido justamente no âmbito da literatura infantil que Lobato obteve seu maior êxito. Ele ilustra com clareza o processo de mercantilização da cultura e, de maneira significativa, da literatura infantil brasileira. O ofício de tradutor tampouco parece destoar do quadro esboçado. Mais uma vez, a sagacidade de Lobato percebe a aliança que faz da tradução um porto seguro para as editoras atentas a um mercado sôfrego por novidades.

A novidade era absoluta. Livros novos, arejados, cinematográficos, de cenários amplíssimos - não mais a alcova de Paris. Almas novas e almas fortes, violentíssimas, caracteres shakespeareanos, kiplinguianos, jacklondrinos - novos, fortes, sadios. E deliciado com tanto novo, o público passou a pedir mais, mais, mais, até que se saturou, ou antes, que as editoras saturaram o mercado (LOBATO, 1964, p. 125). 
Assim, diante da configuração de um mercado ansioso por lançamentos novos e sob o impacto de sua derrocada financeira nos EUA que Lobato assume inteiramente o ofício de tradutor. Ao amigo Godofredo Rangel, escreve entusiasmado e relata, "Tenho empregado as manhãs a traduzir. Imagine só a batelada de janeiro até hoje: Grimm, Andersen, Perrault (...)" (LOBATO, 1964, II V., p. 366).

\section{Os Grimm no Sítio do Picapau Amarelo}

Data, portanto, de 1934 o Contos de Grimm: tradução e adaptação de Monteiro Lobato. Neste volume, encontram-se vertidas para o público brasileiro onze das duzentas e dez narrativas provenientes da coletânea alemã Contos maravilhosos para as crianças e para o lar (Kinder-und Hausmärchen, 1982) ${ }^{3}$, como "A menina da Capinha Vermelha" ("Rotkäppchen"), "Cinderela" ("Aschenputtel"), "As enteadas e os anões" ("Die drei Männlein im Walde"), "O Príncipe Sapo" ("Der Froschkonig oder der eiserne Heinrich"). A essa publicação, segue-se, dois anos depois, um segundo volume, Novos Contos de Grimm, onde aparecem o "Rumpelstiltskin", ("Rumpelstiltskin"), "Os dois irmãozinhos" ("Brüderchen und Schwesterchen"), "Rapunzel" ("Rapunzel”), dentre outros. Contudo, ao leitor atento, não passará despercebido o subtítulo dado aos dois volumes - tradução e adaptação de Monteiro Lobato - como também talvez lhe intrigue o idioma do texto de partida. De fato, quem esquadrinhar a correspondência do escritor com o amigo Godofredo Rangel encontrará indícios que sugerem o fato de Lobato ter feito sua "tradução e adaptação" com base em traslados anteriores. A seu favor, entretanto, é preciso advertir que o mercado brasileiro editorial, nesse movediço terreno da tradução, estava ainda se constituindo, e muitos tradutores, dado o pouco prestígio da profissão, acobertavam-se sob o anonimato. Lobato não desconhecia o menosprezo, e manifesta-o, escrevendo ao amigo, "(...) traduzi tão brutalmente que me acusaram lá fora de apenas assinar as traduções." (LOBATO, 1964, II V., p.366). 
Com efeito, não faltavam nas residências brasileiras do final do século XIX, e nos primeiros decênios do seguinte, um número considerável de traduções para o inglês e o francês - idiomas que Lobato dominava bem - e mesmo para o português, a exemplo das coleções de Figueiredo Pimentel (Contos da Carochinha, 1894; Histórias do Arco da Velha, 1894; Histórias da Baratinha, 1896; Histórias da Avozinha, 1896). Também aqui, a epistolografia de Lobato, bem como a pesquisa nos arquivos da Biblioteca Nacional, podem constituir vias de acesso importantes para compreender a empresa de Lobato. ${ }^{4}$ Com efeito, evidencia-se não só a leitura lobatiana de coletâneas anteriores à sua, como também o projeto de "abrasileirar" as traduções. Assim, em um de seus artigos, recorta o papel do tradutor - "a universalização do pensamento" - malgrado a baixa remuneração - como também o seu propósito: "Estou a examinar os contos de Grimm, dados pela Garnier. Pobres crianças brasileiras. Que traduções galegais. Temos de refazer tudo isso abrasileirar a linguagem (LOBATO, 1961, p. 237).

Afora os trechos em que comenta a mímica adotada, em Nova Iorque, para se comunicar com um companheiro de jogos de xadrez, alemão, os títulos traduzidos que lê sugerem que Contos de Grimm e Novos Contos de Grimm constituem traduções indiretas, que glosam no estilo direto de Lobato, na sua linguagem simultaneamente inovadora e transparente, a floreada prosa parnasiana das coleções anteriores, como as de Figueiredo Pimentel, pela Livraria Quaresma (Contos da Carochinha, 1894; Historias da Baratinha e Historias da Avozinha, 1896) e as publicadas pela Garnier, com traduções do francês por Luiz Moland e Ernesto Grégoire (Contos dos Irmãos Grimm, 1897). O novo estilo que Lobato imprime em sua adaptação salta à vista a quem faça o cotejo. Se o "Branca como a Neve" de Figueiredo Pimentel, versão nacional do "Schneewittchen", abre a narrativa com uma sucessão de adjetivos, cuja função parece ser a de salientar e equiparar a nobreza de suas virtudes com o desejo de maternidade - "A rainha Laurinda era a soberana mais estimada do mundo, por sua bondade, virtude e bom coração. Para ser completamente feliz, só uma coisa desejava - ter 
filhos" (PIMENTEL, 1958, p. 199). "Era no inverno e os flocos de neve caiam do ceo como fina pennugem. Uma rainha, nobre e bella, estava ao pé da janella aberta do palácio; bordava e ao mesmo tempo olhava os flocos balouçarem-se docemente no ar" (GRIMM, 1897, p. 201). ${ }^{5}$

A tradução de Lobato adapta, de fato, o ócio nobre ao pragmatismo burguês numa linguagem clara e direta, contando que "Era uma vez uma rainha que pregava botões nas camisas do seu esposo, apoiada no parapeito do ébano da varanda do palácio. Estava nevando." (LOBATO, 1958, p. 64). Se o estilo de Lobato rompe com a prosa ornamental dos textos precedentes e com a clara moral cristã, tampouco abandona o mesmo tom de zombaria que seria característico de sua obra - aquele que marcaria de modo implacável a voz da célebre personagem, Emília. "A rainha ficou furiosa", conta o narrador de Lobato, "e quebrou quanta coisa havia no quarto, inclusive o espelho." (LOBATO, 1958, p. 77). Não poderá deixar de sorrir o leitor, ou ouvinte, diante do destino dado ao objeto que, servindo emblematicamente à vaidade da madrasta, desempenhara na economia do conto a função de assinalar o amor narcísico. Lobato, embora preso às teias da tradução, não resiste à sua tendência a desconstruir a moral edificante, característica dessas narrativas.

Procedimento similar pode ser lido igualmente na tradução e adaptação do "Schneeweisschen und Rosenrot", narrativa que passara a integrar o acervo dos Irmãos Grimm somente a partir da terceira edição (1837). O conto, embora não conste do repertório publicado por Pimentel, pode ser lido na tradução dada pela Garnier, em fins do século XIX, a qual Lobato tivera acesso, como visto em sua crítica. Assim, se cotejadas, a titulo de exemplo, as cenas iniciais do conto na versão da Garnier e na oferecida por Lobato, não será difícil perceber também ali a tendência do escritor brasileiro a condensar o texto, atendo-se ao núcleo de interesse da narrativa. Com efeito, se a tradução do Molland e Grégoire estende-se mais na descrição da figura materna, definindo-a como uma "pobre viúva" que vive "longe da cidade n'uma choupana muito pequenina." (GRIMM, 1897, p 122), a de Lobato, veremos 
adiante, mais concisa, escolhe a linguagem corriqueira dos brasileiros. "Era uma vez uma pobre viúva que vivia longe da cidade n'uma choupana muito pequenina. Em frente da choupana havia um jardimsinho [sic] com duas roseiras, uma dava rosas brancas, a outra rosas vermelhas" (GRIMM, 1897, p. 122).

A sua condição social, assim especificada, convoca o leitor não apenas a contemplar a vida piedosa e aplicação ao trabalho de suas duas filhas, mas, sobretudo, pela repetição dos advérbios de intensidade (tão) e pela oração exclamativa, sublinha o valor de qualidades como a devoção cristã, a bondade e a dedicação às tarefas do lar, agenciadas pelo conto.

A viúva tinha duas filhas que se pareciam com as duas roseiras; uma chamava-se Branca-de-Neve, e a outra, RosaVermelha. Eram tão devotas, tão boas, tão trabalhadoras e sempre tão de bom humor! Nunca na terra houve crianças tão gentis [...] ( GRIMM, 1897, p. 122).

É interessante observar que a tradução e adaptação de Lobato, "Branca de Neve e Rosa Vermelha" (Contos dos Irmãos Grimm), ainda que não se desvie do modelo inspirado pelo elogio de certas qualidades morais, ela as atenua significativamente o componente religioso optando igualmente por estilo bem mais coloquial.

Era uma vez uma viúva que morava em uma casinha com duas filhas, As meninas chamavam-se Branca de Neve e Rosa Vermelha, por serem como as rosas que desabrochavam nos dois canteiros em frene da casinha. Eram tão boas, trabalhadeiras e direitinhas que só vendo [...] (LOBATO, 1958, p. 52).

Nota-se, assim, que Lobato opta por seleção vocabular bem mais próxima ao público brasileiro de início do século $\mathrm{XX}$, em 
acordo ao seu propósito de abrasileirar a linguagem, e simultaneamente destaca e/ou atenua passagens em desacordo à sua formação pragmática e esclarecida. Desse modo, qualificativos como "devota" são trocados por "direitinhas".

De fato, quem percorre a correspondência do autor sabe que a ruptura com o modelo instaurado, não é fruto do acaso, mas de uma concepção aguda do papel do tradutor como leitor em trânsito entre culturas e linguagens. Não é, pois, de se estranhar a arguta consciência do escritor quanto ao elo que une tradução e leitura, como operações indissociáveis, seja porque todo ato de leitura consiste numa operação de tradução, seja porque, para Lobato, traduzir implica necessariamente ler e atualizar o texto a ser vertido. Com perspicácia, observa que "há muitas maneiras de ler. Talvez a mais profunda seja a de quem verte um livro para outra língua." (LOBATO, 1961, p. 237). Reconhecendo, portanto, a operação de leitura como suporte que sustenta o exercício da tradução, Lobato identifica o fosso que separa as traduções portuguesas do leitor brasileiro. De fato, Dona Benta, espécie de alter-ego do leitor-Lobato, sabe traduzir os livros portugueses em linguagem adequada aos cidadãos que deseja formar

A moda de D. Benta ler era boa. Lia diferente dos livros. Como quase todos os livros para crianças que há no Brasil são muito sem graça, cheios de termos do tempo do Onça ou só usados em Portugal, a boa velha lia traduzindo aquele português de defunto em língua do Brasil de hoje (LOBATO, 1959, p. 191).

Desse modo, as personagens do acervo compilado pelos Grimm migram, pela leitura de Lobato, para o Sítio do Picapau Amarelo, lugar simultaneamente idílico e voltado à formação de leitores. $\mathrm{O}$ espírito de insubmissão, flagrado nas traduções e adaptações, assoma na obra criada para o público infantil brasileiro, desconstruindo claramente, em jogos intertextuais, qualquer sinal de reverência aos clássicos da literatura. 
Assim, se é verdade, como visto, que Lobato reconhecia os liames que unem o trabalho da tradução e a operação de leitura, não é fortuito que atualizasse, em D. Benta, espécie de leitor/tradutor, sua ideia de tradução. Por esta via, por intermédio da voz de D. Benta, e dos habitantes do sítio, o leitor que atravessava o umbral da fazenda, ingressava em espaço simultaneamente local e universal. O mesmo projeto que fundamentava sua criação para o público infantil - atento, de um lado, às questões do mercado editorial e, de outro, à necessária renovação da escrita e concepção dos textos dirigidos à infância, parece, pois, nortear os traslados do acervo pré-existente. Desse modo, concebendo a tradução como leitura, particularmente atento às injunções do público alvo, não se intimida diante do clássico herdado da cultura romântica alemã e das versões em circulação no país, como as de Figueiredo Pimentel e as da Garnier. A atitude insubmissa de Lobato que lhe permite, na obra iniciada com o Narizinho Arrebitado (1921), os jogos intertextuais e antropofágicos face à figuras tão representativas como Pequeno Polegar, A Gata Borralheira, Peter Pan, D. Quixote, etc - se converte, na tradução e adaptação do Contos de Grimm e Novos Contos de Grimm, em atitude de familiarização do acervo transmitido. Efetivamente, seja porque entende a tradução como operação "que conta em palavras suas" (LOBATO, 1964, p. 128) o texto estrangeiro lido, seja porque percebesse a urgência em verter a compilação dos Grimm em língua do Brasil de sua época, Lobato domestica os contos reunidos pelos irmãos alemães. A atitude deflagrada no trabalho de verter para a língua portuguesa contemporânea a literatura infantil canônica estrangeira parece, assim, associar-se ao conjunto da obra lobatiana, intensamente preocupada com a reinvenção da língua nacional (LAJOLO, 2009). Tal posição, entretanto, se hoje poderia ser apreendida como postura etnocêntrica conforme proposição de Bermann (1984), tem a seu favor a lembrança de que, à época de Lobato a tradução não consistia ainda em profissão regulamentada, e suas bases teóricas tampouco eram alvos dos intensos debates e da expansão disciplinar, como os que hoje assistimos (GUERINI, TORRES, COSTA, 
2013). De fato, como bem adverte Paes (1990), é somente a partir da década de 30, no século XX, que começa a se esboçar, no país, a tradução literária como atividade profissional Ademais, cumpre salientar que o criador de Narizinho não mascarou a proposta de ajustar o que circulava no Brasil ao público infantil. Efetivamente, as duas obras carregam o título e intenção que guia o seu projeto - Contos de Grimm e Novos Contos de Grimm, tradução e adaptação de Monteiro Lobato. Os nomes estampados assim na capa denunciam a aliança e, muito mais do que ensejar etnocentrismo, o que testemunham é a intenção de hospedar o acervo estrangeiro. Um pouco à moda de D. Benta, ao acolher nas terras Novas do Sítio do Pica-pau Amarelo, todo o universo maravilhoso. Afinal, como disse a boa velha, "Em mil e duzentos alqueires de terra (...) cabem todos os personagens do Mundo das Fábulas" (LOBATO, 1965, p 11).

\section{Notas}

1. Utilizar-se-á para as citações do livro, sua tradução para o espanhol.

2. Optou-se por manter as citações na língua do texto lido, traduzindo-se apenas os trechos em alemão.

3. A coletânea intitulada Kinder-und Hausmärchen (1982) pareceu inicialmente em dois volumes, em 1812/15. A esta edição seguiram-se ainda outras sete. $\mathrm{O}$ estudo comparado das edições e manuscritos permite averiguar o processo de censura e filtragem inerente à adaptação para o público da Haus burguesa.

4. A pesquisa nos arquivos da Biblioteca Nacional permitiu a identificação das traduções aqui mencionadas. As coletâneas de F. Pimentel con- 
stituem, em realidade, uma reunião de contos retirados da tradição oral, adaptados para as famílias brasileiras, com edição da Livraria Quaresma; os contos publicados pela Livraria Garnier (Contos dos Irmãos Grimm, 1897) foram impressos em Paris e são traduções do alemão, informa-o a nota do editor, para o português, por Luiz Molland e Ernesto Grégoire.

5. Adotou-se a ortografia original

\section{Referências}

BERMAN, Antoine. L'épreuve de l'étranger. Culture et traduction dans l'Allemagne romantique. Paris: Gallimard, 1984.

BRÜDER GRIMM. Kinder-und Hausmärchen. Stuttgart: Philipp Reclam, 1982.

BRUNEL, P.; PICHOIS, C.; ROUSSEAU, A-M. Que é literatura comparada. São Paulo: Perspectiva, 1990.

CHEVREL, Yves. Le texte étranger: la littérature traduite. In: ; BRUNEL, Pierre (Org.). Précis de littérature comparée. Paris: Presses Universitaires de France, 1989. p. 57-83.

FIORENTINO, Teresinha Aparecida del. Prosa de ficção em São Paulo: Produção e consumo (1900-1922). São Paulo: Hucitec, 1982.

GRIMM. Contos dos Irmãos Grimm. Trad. Ernesto Grégoire e Luiz Mollland. Rio de Janeiro: H. Garnier, ${ }^{\odot} 1897$.

GUERINI, Andréia. TORRES, Marie-Helène Cattherine, COSTA, Walter Carlos. (Org.). Tubarão; Ed Copiart; Florianópolis; PGET/UFSCC, 2013. 
JAKOBSON, Roman. Aspectos lingüísticos da tradução. In: . Lingüística e comunicação. $20^{\text {a }}$ ed. Trad. Izidoro Blikstein e José Paulo Paes. São Paulo : Cultrix, 1995. p. 63-72.

LOBATO, José Bento Monteiro. A Barca de Gleyre. $3^{\mathrm{a}}$ ed. São Paulo: Brasiliense, 1964. 2v. V.2

. Contos de Grimm. 10 ed. São Paulo: Brasiliense, 1958.

. Mundo da lua e miscelânea. $11^{\text {a }}$ ed. São Paulo: Brasiliense, 1964.

. Reinações de Narizinho. 20 ed. São Paulo: Brasiliense, 1959.

. Conferências, artigos e crônicas. 2ª ed. São Paulo: Brasiliense, 1961.

. Fábulas e estórias diversas. $13^{\text {a }}$ ed. São Paulo : Brasiliense, 1965.

LAJOLO, Marisa. A modernidade em Monteiro Lobato. In: ZILBERMAN, Regina (Org.). Atualidade de Monteiro Lobato. Porto Alegre, Mercado Aberto, 1983.

. Linguagens $n a$ e $d a$ literatura infantil de Monteiro Lobato. IN: LAJOLO, Marisa; CECCANTINI, João Luís. (Org.) Monteiro Lobato, livro a livro: obra infantil. São Paulo: UNESP, 2009.

LARROSA, Jorge. La experiencia de la lectura: estudios sobre literatura y formación. 2 ed. Barcelona: Laertes, 1996

PAES, José Paulo. Tradução: a ponte necessária. São Paulo: Ática; Secretaria de Estado da Cultura de São Paulo, 1990.

PIMENTEL, Figueiredo. Contos da Carochinha. $25^{\text {a }}$ ed. Rio de Janeiro: Livraria Quaresma, 1958.

STEINER, George. Después de Babel. 3 ed. Tradução de Adolfo Castañon e Aurelio Major. México: Fondo de cultura económica, 2001. Título original: After Babel. 
VENUTI, Lawrence. Escândalos da tradução. Trad. Lauruano Pelegrin, Lucinéia Marcelino Villela, Marileide Dias Esqueda e Valéria Biondo. Bauru: EDUSC, 2002. Título original: The Scandals of Translation.

Recebido em: 13/08/2015 Aceito em: 12/10/2015 